stati assegnati ai gruppi A/C1, F e I1.

Conclusione. I risultati ottenuti dimostrano come l'identificazione dei repliconi possa essere uno strumento utile per la descrizione di plasmidi correlati, permettendo la descrizione di nuovi scenari epidemiologici sulla diffusione dei geni che conferiscono la resistenza agli antibiotici.

041

\title{
PLASMIDI EMERGENTI CONFERISCONO LA RESISTENZA A CEFALOSPORINE E CARBAPENEMICI
}

Villa' L., Bertini' A., Miriagou² V., Loli A.; Colinon³ C., Rossolini ${ }^{3}$ G.M., and Carattoli' A.

Istituto Superiore di Sanità, viale Regina Elena 299, 0016 I, Roma, Italia'; Institute Pasteur, Athens, Greece; Università di Siena, Siena, Italia².

\section{Introduzione.}

I geni che conferiscono la resistenza agli antibiotici possono essere localizzati su plasmidi a largo spettro d'ospite e mediante questi possono essere trasferiti tra specie non correlate. Il nostro gruppo ha recentemente messo a punto un nuovo metodo di tipizzazione dei plasmidi per PCR, basato sull'identificazione delle sequenze che regolano la replicazione (repliconi) permettendo di riconoscere plasmidi filogeneticamente correlati. Lo scopo di questo studio è stato inizialmente quello di verificare l'applicabilità e la sensibilità del metodo su collezioni di plasmidi isolati da batteri patogeni circolanti in USA, Grecia ed Italia, caratterizzati dalla presenza di metallo-ß-lattamasi o AmpC-ß-lattamasi o ß-lattamasi a spettro esteso. Questa analisi ha quindi permesso di identificare plasmidi emergenti che veicolano geni di resistenza molto diffusi.

Metodi.

Il metodo di identificazione dei plasmidi per PCR riconosce 18 differenti repliconi tra quelli più comunemente descritti in Enterobacteriaceae ed è stato applicato a 26 plasmidi che portano uno o più geni tra $b l a_{\mathrm{cmy}-2}, b l a_{\mathrm{cmy}-4}, b l a_{\mathrm{cmy}-13}, b l a_{\mathrm{vim}-1}$, bla $_{\text {vim-4 }}$ e bla $a_{\text {siv-12. }}$.

\section{Risultati.}

I plasmidi bla $a_{\mathrm{cmy}-2}$ isolati in USA da Salmonella enterica e Escherichia coli O157:H7 sono positivi per repA/C2 e repI1. $\mathrm{Al}$ replicone $\mathrm{A} / \mathrm{C} 2$ sono risultati positivi anche altri due plasmidi che portano i geni bla cmy-4 $_{\text {e }}$ blavim-4 isolati in Italia da ceppi clinici di Klebsiella pneumoniae ed Enterobacter cloacae, suggerendo una grande diffusione di questo tipo di plasmidi. Tutti i plasmidi blavim-1, identificati in K. pneumoniae e E. coli in Grecia, sono risultati positivi per il replicone N, dimostrando un'inattesa correlazione epidemiologica tra questi isolati. Cinque plasmidi bla ${ }_{\mathrm{SHV}-12}$ isolati in Italia sono 